\title{
Inteligência Policial e Redes Sociais: a polícia Federal em busca de uma política CONSTITUCIONALMENTE SUSTENTÁVEL ${ }^{1}$
}

\author{
IVON Jorge DA SiLVA \\ Departamento de Polícia Federal - Brasil

$$
\text { 2. }
$$

\begin{abstract}
RESUMO
A atividade de inteligência policial está no centro do debate internacional, sobretudo com o advento da globalização e do desenvolvimento de relações sociais cada vez mais potencializadas por meio de redes de computadores. Em decorrência, novas técnicas precisam ser implementadas pela polícia para fazer frente à criminalidade que avança de forma vertiginosa no mundo virtual. Nesse contexto, surgem questões das mais variadas naturezas, mas, no Estado Democrático de Direito, uma ponderação que não pode ficar à margem diz respeito à proteção da dignidade da pessoa humana e, paralelamente com a polícia nessa proteção. Na busca por estabelecer esta ponderação entre o papel da polícia no enfrentamento da nova criminalidade e à necessária proteção à dignidade humana mesmo nesse novo ambiente, ergue-se com importância vital a política criminal, que orienta as ferramentas adotadas pelo Estado na prevenção e combate à criminalidade. Nesse sentido, questiona-se que orientação deve seguir essa política criminal e em que bases deve estar firmada para que se coadune com o estágio das democracias e dos Estados de Direito que postulam a garantia dos direitos humanos. Conclui-se que para atender aos ditames constitucionais brasileiros, a atuação da inteligência policial deve estar estribada em uma política criminal constitucional que tenha como foco e centro a dignidade humana: uma política criminal do ser humano.
\end{abstract}

Palavras-Chave: Crime. Democracia. Estado de Direito. Política Criminal. Polícia. Inteligência Policial. Redes Sociais.

\section{INTRODUÇÃo}

Norberto Bobbio (1994, p. 208) entende que a democracia, ainda que de forma ideal, é o governo do poder visível. Sendo assim, todos os atos dos mandatários do povo devem passar pelo controle e devem visar o bem

1 Artigo científico apresentado no dia 07/05/2014 à Academia Nacional de Polícia como exigência parcial para a conclusão do Curso de Especialização em Inteligência Policial. O trabalho foi submetido à Banca Examinadora composta pelos Mestres Eliomar da Silva Pereira (Orientador), Luiz Henrique Ungaretti de Godoy e Flávio Rodrigues Calil Daher. 
desse mesmo povo. Não há área ou política implantada que possa se abster de fincar na democracia as suas bases.

Esse norte deve sempre ser revisitado com o passar do tempo, a fim de que sejam evitadas involuções autocráticas ou mesmo autoritárias dentro do próprio Estado Democrático de Direito. Dessa forma, quando se trata da prevenção e repressão à criminalidade, a bússola do legislador, do administrador, do julgador e do executor deve apontar na direção correta.

Assim, as medidas adotadas no campo de embate entre as instituições policiais e a criminalidade devem refletir uma política criminal solidificada nos fundamentos democráticos previamente postos na Constituição. $\mathrm{O}$ mesmo caminho deve seguir os legisladores e os julgadores.

Como a sociedade é dinâmica, os princípios edificadores do Estado devem ser constantemente revisitados quando da implantação de novas políticas e práticas pelos gestores públicos. Postura semelhante deve ser adotada pela polícia ao agir para a prevenção e repressão à criminalidade que ocorre no ambiente das redes sociais de computadores.

A novidade trazida pelas relações havidas no mundo virtual colocou em xeque a forma de atuar do Estado para regular o necessário, atendendo ao princípio de interferência mínima na intimidade e liberdade dos cidadãos, sem arranhar o pacto democrático.

É um aprendizado a cada dia, afinal, num período de cerca de vinte anos a humanidade tem experimentado uma evolução em suas redes sociais compatível com milênios de história. Nesse mar de informações que circulam à velocidade da luz as instituições públicas devem estar preparadas para dar um passo à frente de cada vez, ainda que seja pequeno, sem retroceder aos argumentos de autoridade que tanto mancharam a história das nações.

Neste cenário, é apresentada uma Política Criminal que seja compatível com o Estado brasileiro e que possa desempenhar o papel que se exige de uma verdadeira ciência deste quilate que é ser o elo entre as ações governamentais e os fundamentos maiores da República, em destaque a dignidade da pessoa humana. Essa política criminal não poderia receber outro nome que não o de Política Criminal do Ser Humano. 
Como se cuida de política criminal que aponte o norte, é preciso que a atuação policial siga nessa direção. Para tanto são visitados os papéis de uma polícia republicana e feita uma reflexão entre os intentos do legislador constituinte originário e a prática atual das instituições policiais brasileiras.

Ocorre que a criminalidade, sobretudo na era da informática, tem se apresentado de forma cada vez mais organizada e ardilosa, o que obriga as instituições policiais a lançarem mão de unidades de inteligência altamente especializadas na produção de conhecimento que leve ao desmantelamento dessas redes de criminosos.

Essa atividade de inteligência, para ser democrática, precisa aliar-se à Política Criminal do Ser Humano para alcançar em suas ações legitimidade neste Estado democrático. É apresentado o caminho para que a Inteligência atue de maneira cada vez mais eficaz, sem tirar os olhos do seu verdadeiro fim, que é, além de prevenir e reprimir delitos, contribuir para a solidificação da democracia nacional.

Como o mundo vive na era da informação via computadores, há que se ter entendimento das redes sociais virtuais, os delitos nelas perpetrados e como deve se dar a atuação da inteligência policial da Polícia Federal nesse cenário.

À guisa de conclusão é apresentada uma contextualização maior com a evolução das sociedades democráticas, como forma de conscientizar cada policial que sua atuação reflete e deve reforçar o Estado que conquistamos: o Estado Democrático de Direito.

\section{A Política Criminal do Ser Humano}

O conceito de política criminal não encontra unanimidade no meio acadêmico. Há discussões acerca de seu posicionamento no interior da criminologia ou do direito penal. Ainda, há os que a compreendem como parceira dessas duas áreas. Discute-se até se a política criminal é uma ciência, arte, ou outra forma de manifestação do pensamento acerca do fenômeno criminal.

Todavia, prevalece o entendimento que a criminologia, o direito penal e a política criminal se inserem no âmbito das chamadas "ciências criminais". Sendo assim, a política criminal, que possui campo próprio de atuação, estuda as medidas possíveis para a redução ou impedimento da criminalidade (SHECAIRA, 2013, p. 37). 
Apresentaremos algumas definições de política criminal, para, a partir de então, tratarmos da política criminal do ser humano, concepção que consideramos adequada para este ramo do saber e agir social.

\subsection{Política Criminal}

Franz Von Liszt, (apud Valente, 2013, p. 67) considera a política criminal como: "O conjunto sistemático dos princípios fundados na investigação científica das causas do crime e dos efeitos das penas, segundo os quais o Estado deve levar a cabo a luta contra o crime por meio da pena e das instituições com esta relacionadas."

Após essa definição de política criminal observa-se que a ideia apresentada no início desse trabalho por Sérgio Salomão Shecaira (2013, p. 37) encontra respaldo nesse autor (LISZT, 2006, p. 3), o qual reforça o entendimento de tratar-se a política criminal de uma ciência no trecho seguinte:

A esta sciencia incumbe dar-nos o critério para apreciarmos o valor do direito que vigora, e revelar-nos o direito que deve vigorar; cabe- lhe ensinar-nos tamberm a entender o direito á luz de consideraçôes tiradas dos fins a que elle se dirige e a applica-lo em casos singulares de conformidade com esses fins.

A política criminal insere-se no campo das ciências humanas ou sociais. Sendo assim, baseada em um método empírico de análise e observação da realidade, constrói conhecimento, este de extrema utilidade para a harmonização e efetividade das ciências criminais, sobretudo do direito penal e da criminologia.

No cenário de embate ao fenômeno da criminalidade, embora atuem em sintonia e possuam o mesmo objetivo, direito penal, criminologia e política criminal possuem cada qual espaço próprio e diferentes meios de atingir esse objetivo.

Esse elo entre as ciências se mostra evidente nas palavras de Sérgio Salomão Shecaira (2013, p. 42):

A politica criminal é uma disciplina que oferece aos poderes públicos as op̧õoes científicas concretas mais adequadas para controle do crime, de tal forma a servir de ponte eficaz entre o direito penal e a criminologia, facilitando a recep̧̧ão das investigaçōes empiricas e sua eventual transformação em preceitos normativos. Assim, a criminologia fornece o substrato empirico do sistema, seu fundamento 
científico. A politica criminal, por seu turno, incumbe-se de transformar a experiência criminológica em opçóes e estratégias concretas assumiveis pelo legislador e pelos poderes públicos.

Acerca do caráter científico da política criminal existe fértil debate, que se dá, em parte, pela inexatidão própria das ciências humanas. Alguns autores como Sérgio Salomão Shecaira (2013, p. 42) consideram que a política criminal não está no mesmo patamar científico da criminologia e do direito penal. Alegam que ela não possui método próprio e está ramificada entre os diversos entes estatais.

Visão semelhante compartilha Enrico Ferri (2009, p. 68-69), para quem o conceito de política criminal como ciência de Franz Von Liszt é inexato, ao passo que a considera como uma arte, "a arte do legislador em utilizar, adaptando-as às condições do próprio país, as conclusões e as propostas que a ciência dos crimes e das penas lhe apresenta."

Essa discussão, embora mereça aprofundamento em obra específica, acaba por demonstrar não apenas um questionamento da cientificidade da política criminal, mas, uma constatação - de importância capital para o tema aqui proposto - de que ela possui tal capilaridade no contexto de atuação dos entes estatais, que lhe permite dispor de instrumentos dessas diversas áreas para o entendimento, prevenção e repressão à criminalidade.

A capilaridade da política criminal é identificada por Germano Marques da Silva (2000, p. 38) ao identificá-la como critério orientador da legislação e dos projetos e programas sociais voltados à prevenção e repressão da criminalidade.

Américo Taipa de Carvalho (2011, p. 12,13) vai além na defesa do papel da política criminal, pois, considera-a como ciência com supremacia sobre o direito penal positivo, por conter, segundo seu entendimento, os princípios éticos individuais e sociais que devem promover, orientar e controlar a luta contra a criminalidade.

Resta claro que as diversas tentativas de definir política criminal procuram respostas para a criminalidade, seja do ponto de vista da prevenção ou da repressão. Tais respostas, que cabem ao Estado, ora envolvem mais ora menos a sociedade, estudam dados fornecidos pela criminologia e resultados obtidos na aplicação do direito penal posto. 
Como acompanha o movimento social, a política criminal, em certa visão, está em constante mutação, à medida que se alternam as forças políticas no poder, sendo este um dos principais argumentos daqueles que não a consideram uma ciência. Já aqueles que consideram a política criminal uma ciência, defendem que ela utiliza os mesmos métodos das demais ciências sociais.

A questão mais relevante entre os conceitos apresentados até aqui, ou mesmo o ponto de convergência, é o papel de destaque que alcançou a política criminal na busca do Estado e da sociedade por respostas aos ataques ao "pacto social".

Diante da importância da política criminal para a manutenção ou transformação do status quo social, aflora a necessidade de identificar um sistema de política criminal que seja o mais adequado à garantia da dignidade humana no Estado Democrático de Direito.

\subsection{Política Criminal do Ser Humano}

A política criminal focada na dignidade humana recebeu de Manuel Monteiro Guedes Valente (2013a, p. 21) a designação de Política Criminal do Ser Humano. Não se trata apenas de uma nomenclatura, mas uma política criminal que aspire ser assim reconhecida deve preencher diversos requisitos históricos, espaciais e constitucionais, os quais serão aqui apresentados.

Para uma boa compreensão do caminho a percorrer, serão apresentados algumas fontes nas quais o Estado se baseia na adoção de determinada política em face da criminalidade. Entre as fontes mais importantes de conhecimento e análise do crime no seio social estão as escolas sociológicas do crime, que fornecem os substratos da criminologia, ou seja, as diversas explicações da criminalidade.

Essas escolas se baseiam em realidades sociais específicas, possuem focos variados - meio ambiente, relações sociais, classes, grupos, etnias, raças, conflitos sociais, estruturas econômicas, entre outros - ainda, os estudos criminológicos por elas concretizados encontram-se atrelados a momento histórico específico, o que aponta para o grande dinamismo dos estudos criminológicos, o qual, muitas vezes não é acompanhado pelo direito positivado. 
Alguns exemplos de escolas sociológicas do crime, vertentes da criminologia, são a Escola de Chicago, a Teoria da Associação Diferencial, a Teoria da Anomia, a Teoria da Subcultura Delinquente, o Labelling Approach e a Teoria Crítica. Os ensinamentos trazidos por essas diversas vertentes se agregam para disponibilizar ao Estado conhecimento que o oriente no momento de formular a política criminal e a criação de leis penais e processuais penais.

Ocorre que, ao seguir determinada escola como parâmetro para a adoção das políticas sem fazer as necessárias adaptações (baseadas também em estudos científicos), grandes equívocos são experimentados pelo Estado, uma vez que a simples importação de experiências criminológicas que apresentaram resultado satisfatório em outro momento histórico, outra realidade social, outro ambiente, outra cultura, não garante os mesmos resultados.

Observa-se que a política criminal que faz essa leitura descontextualizada do conhecimento fornecido pela criminologia está sempre a um passo do movimento criminoso local. Muitos fatores, porém, levam os governantes e legisladores a importarem modelos e aplicá-los de forma hermética, sem um debate com a própria realidade. Entre eles estão a necessidade de resposta imediata a delitos que causam grande comoção social, interesses eleitoreiros, desejo de promoção pessoal.

Como cabe à política criminal as estratégias a serem adotadas pelo Estado no controle da criminalidade, essa ciência é a que mais sofre com a adoção de medidas equivocadas. Daí alguns autores firmarem posição de que não cabe a ela o status de ciência, e sim de arte, ofício à disposição dos governantes.

Com a adoção desse entendimento, estariam as democracias em situação de extrema instabilidade, vez que dependentes dos resultados regulares das urnas para se firmarem. É corrente que a realidade acontece de maneira diversa, os governantes obrigam-se a agir conforme as bases constitucionais firmadas pelo constituinte originário ou arriscam-se a ser depostos de seus cargos.

Em nome da segurança jurídica ergue-se então a política criminal, como ciência com a responsabilidade de apontar o caminho mais seguro contra os apelos imediatistas e antidemocráticos. Nota-se assim que a política criminal não pode estar nas mãos dos governantes, mas deve ser reconhecida como uma ciência de observância obrigatória pelos chefes dos poderes, vez que fundamentada nos princípios constitucionais. 
Aliado a esse raciocínio, Manuel Monteiro Guedes Valente (2013a, p. 31-32) afirma que não há uma realização dogmática jurídico-criminal, garante da segurança jurídica sem a intervenção da política criminal como ciência essencial ao apuramento e conhecimento crítico da realidade criminógena transmitida pela criminologia.

Dessa forma, à política criminal caberia a interpretação da realidade criminal de cada momento histórico, a partir de dados fornecidos pela criminologia - referentes àquele espaço - e a partir dos elementos coletados e trabalhados, apontar aos governantes, legisladores, administradores e juristas, as estratégias mais apropriadas à prevenção e repressão dos delitos.

Questão central se impõe acerca do papel da política criminal, qual seja, em que bases estaria assentada essa ciência a fim de proporcionar, sobretudo nas democracias, a segurança necessária aos cidadãos frente às instituições estatais.

A resposta é apontada por Manuel Monteiro Guedes Valente (2013a, p. 32-33) ao dizer que a política criminal regente da ação penal deve estar vinculada aos valores constitucionais do Estado de direito e democrático.

A política criminal no Estado Democrático de Direito, definitivamente, ganha status constitucional, o que significa dizer que os princípios e normas constitucionais de garantia dos direitos humanos devem, necessariamente, estar inseridos em todas as políticas de enfrentamento da criminalidade, independentemente dos motivos apresentados pelo implantador da política. Assim considerando, a política criminal constitucionalizada agiria como fiel da balança em todas as medidas legislativas, administrativas e judiciais voltadas à prevenção criminal.

Uma política criminal com essas características teria segundo Manuel Monteiro Guedes Valente (2013a, p. 35) a dignidade da pessoa humana como ator principal, pilar do Estado Democrático de Direito e fundamento, razão e limite dos operadores judiciários na materialização dessa política.

Eis a política criminal do ser humano, seus contornos gerais aqui apresentados dão idéia de sua importância. E encontra definição apropriada em Manuel Monteiro Guedes Valente (2013a, p. 81-82): 
A política criminal, como ciência não jurídica, mas que desenha o conteúdo e os fins do Direito penal, ciência jurídica, é, tendo em conta as várias posiçôes expostas, a ciência que, subordinada aos vectores da legitimidade e da eficácia e aos princípios ético-filosófico-jurídicos da legalidade, da culpabilidade, da ressocialização e da humanidade, deve debruçar-se sobre as causas do crime, sobre a correcta redacção dos tipos legais de crime de modo a corresponderem à realidade delituosa, sobre os efeitos das sanções penais, sobre o limite de extensão da aplicação do Direito penal de que dispóe o legislador penal face à liberdade do cidadão e, ainda, sobre a adequação do Direito penal material ao Direito processual penal, cujo desafio é orientar o Direito penal no cumprimento da missão de proteç̧ão da sociedade sem niilificar as liberdades individuais. (negritos do autor).

Condensando a idéia de política criminal do ser humano como uma ciência ao lado das demais encarregadas da prevenção do crime, teríamos a relação abaixo apresentada:

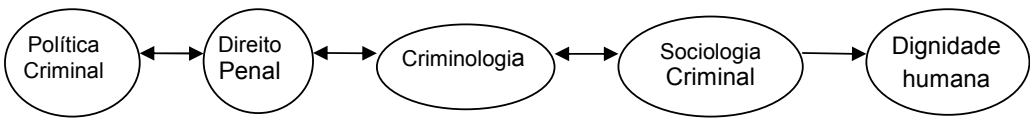

Explicando: A política criminal, o direito penal positivo, a criminologia e a sociologia criminal, entre outros ramos das ciências humanas, produzem saber científico, se comunicam, trocam informaçôes com um fim específico: prevenir o fenômeno criminoso. Todavia, no Estado Democrático de Direito esses conhecimentos e ações devem, necessariamente, estar voltados para a preservação da dignidade da pessoa humana.

\subsection{A Política Criminal do Ser Humano e a Atuação Policial}

Em linhas gerais, apresentamos algumas definições de política criminal e adotamos o conceito de política criminal do ser humano como aquele apto a informar a ação da polícia em todas as suas atividades e, especificamente no objeto que neste trabalho será tratado, a atuação das Unidades de inteligência policial da Polícia Federal junto às Redes Sociais da Rede Mundial de Computadores.

Se a política criminal deve atender ao fundamento constitucional de proteção à dignidade da pessoa humana, a polícia como órgão executor de diversas ações estatais no enfrentamento da criminalidade deve pautar suas ações por essas diretrizes. 
Tal desiderato somente será levado a efeito a partir do momento em que a polícia se veja e se faça ver como órgão de Estado e não de governo - batalha que se inicia com a conscientização interna - autorizado pela Constituição a refutar qualquer ordem ou atitude que extrapole a garantia dos direitos humanos.

Por outro viés, ao planejar suas estratégias de ação sejam administrativas, preventivas ou repressivas, as instituições policiais devem ter como valor maior a dignidade humana, ainda que essa orientação signifique abrir mão de medidas que apresentem resultados - aparentemente - melhores contra determinado segmento criminoso.

Esse entendimento é traduzido de forma bastante clara por Manuel Monteiro Guedes Valente (2013a, p. 37):

A actividade (preventiva e repressiva) da Polícia - não só os actos de prevenção no quadro criminal (onde incluimos a prevenção criminal stricto sensu ou «luta contra a criminalidade»), como também os actos administrativos preventivos e de fiscalização administrativa $e$ os actos operativos policiais - deve materializar a prossecução dos vectores e dos principios enformadores de uma politica criminal subordinada aos valores è s proposiçôes constitucionais de um Estado de direito e democrático, assente na dignidade da pessoa humana. Essa prossecução implica uma Polícia de actuação de defesa e de garante dos Direitos Humanos: identidade da Polícia da pós-modernidade.

Face à constatação acima, cabe à Polícia Federal assumir a dianteira desse movimento de libertação das polícias das amarras de governantes que vêem os órgãos policiais apenas como braço armado do Estado à disposição das ordens dos governos.

A democracia constitucional não mais admite órgãos que se intitulem executores, sem questionar o seu papel, pensado pelo legislador constituinte originário, de contribuição para a manutenção e aperfeiçoamento da própria democracia. Nesse passo, a Polícia Federal, órgão constitucional, deve estar apta a desempenhar os desideratos estatais apresentados por uma política criminal do ser humano, também assentada em bases constitucionais.

Não é outro o entendimento de Manuel Monteiro Guedes Valente (2013a, p. 51): 
Neste contexto encontra eco uma Polícia ao serviço do cidadão e ao serviço da comunidade, que, mesmo em conflito com a comunidade criminógena, se exige guardiã da dignidade humana de todo o delinqüente. Tem eco uma polícia centrada numa politica criminal humanista e garantista subordinada aos valores jus constitucionais e jus internacionais, consagrados na DUDH (Declaração Universal dos Direito do Homem) e CEDH (Convenção Européia dos Direitos do Homem).

Acreditamos estarem bem assentadas as bases da política criminal do ser humano, que tem lugar no Estado Democrático de Direito. E, como um dos principais operadores, a polícia, defensora da dignidade da pessoa humana nesse Estado.

A partir do momento em que a ciência Política Criminal do ser humano estiver em operação, perpassando com autonomia os diversos governos que se sucedem no poder, entendemos que estará sendo dado mais um passo rumo à segurança jurídica e a afirmação dos fundamentos da democracia no Brasil.

Como um dos braços operativos dessa política criminal, uma polícia cada vez mais consciente do seu papel tornará cada vez mais visíveis e respeitados os limites de interferência estatal na esfera de liberdade do cidadão. E o respaldo para esse agir da polícia em defesa da dignidade da pessoa humana encontra-se na própria Constituição Federal, que em seu artigo 144, caput, constitucionalizou a segurança, a cargo das polícias, tendo como um dos principais objetivos a preservação da incolumidade das pessoas. Nas palavras de Manuel Monteiro Guedes Valente (2013b, p. 22), essa liberdade é fundamento e limite da segurança prestada pelo Estado por intermédio da polícia.

Cabe neste instante a memória de que as raízes da valorização que se deve dar à liberdade individual remontam a um período prévio à existência do Estado como o conhecemos e, inclusive, condicionante da sua formação. Daí não poder ser esquecida ao longo da história. ${ }^{2}$

Cesare Beccaria (p. 21) leciona acerca do momento e porque desse sacrifício da liberdade individual:

Cansados de só viver em um continuo de guerra e de encontrar inimigos por toda parte, cansados de uma liberdade tornada inútil por

2 Vale ressaltar que a ideia de um Estado Civil tem defesas muito distintas, como as de Hobbes, Locke e Rousseau. Todavia, para os objetivos deste artigo, nos filiamos ao exposto por Cesare Beccaria. 
causa da incerteza de sua conservação, sacrificaram uma parte dela para gozar do resto com mais segurança. A soma de todas essas porçôes de liberdade, sacrificadas assim ao bem geral, constitui a soberania de uma nação; e aquele que foi encarregado pelas leis do depósito das liberdades e dos cuidados da administração foi proclamado o soberano do povo.

O autor (BECCARIA, p. 23) aprofunda-se no tema e apresenta fundamentos e limites para o direito de punir do Estado, o qual, ao fugir desses limites, se apresenta arbitrário:

O conjunto de todas essas pequenas porções de liberdade é o fundamento do direito de punir. Todo exercício do poder que se afastar dessa base é abuso e não justiça; é um poder de fato e não de direito. As penas que ultrapassam a necessidade de conservar o depósito da saúde pública são injustas por sua natureza; e tanto mais justas serão as penas quanto mais sagrada e inviolável for a segurança e maior a liberdade que o soberano conservar aos súditos.

A segurança pública exercida pela polícia deve ser exercida com olhos fixos nos motivos próprios da formação do Estado. Sobretudo com atenção redobrada para a manutenção da maior fatia possível de liberdade em poder dos cidadãos.

Diversa não pode ser a interpretação, vez que a própria República Federativa do Brasil tem em sua base, como um dos fundamentos de sua existência, a dignidade da pessoa humana, impressa, de forma indelével no inciso III do artigo $1^{\circ}$ da Constituição Federal.

\section{A Inteligência Policial como Instrumento da Política Criminal do Ser Humano}

A atividade de inteligência encontra diversas definições, a depender do usuário, do país, da área de interesse, entre outros. Todavia, para fim do presente estudo, cabe a definição apresentada pela lei no 9.883, de 07 de dezembro de 1999 , que em seu art. $1^{\circ}$, parágrafo $2^{\circ}$, dispõe:

Para os efeitos de aplicação desta Lei, entende-se como inteligência a atividade que objetiva a obtenção, análise e disseminação de conbecimentos dentro e fora do território nacional sobre fatos e situações de imediata ou potencial influência sobre o processo 
decisório e a ação governamental e sobre a salvaguarda e a segurança da sociedade e do Estado.

Percebemos, de pronto, que segundo o entendimento oficial brasileiro a inteligência é atividade e, por ser pública, deve ser desempenhada por agentes públicos, cujo objetivo é obter, analisar e disseminar conhecimentos de interesse do Estado, representado pelo tomador de decisão oficial.

O legislador brasileiro, além de ter apresentado o dinamismo da atividade de inteligência como atividade de apoio a decisões dos gestores públicos diante de oportunidades e riscos, advindos do exterior e mesmo internos, também ressalta o caráter democrático dessa atividade ao atribuir-lhe parcela de responsabilidade na salvaguarda e segurança da sociedade - leia-se população e indivíduo - e do próprio Estado democrático de direito.

O âmbito policial, como extensão da presença estatal, embora com suas peculiaridades também carece da atividade de inteligência, seja em sua esfera de ação estratégica seja no campo operacional ou tático. Afinal, o material produzido pelas unidades de inteligência proporcionará ao tomador de decisão conhecer detalhes sobre cenários de atuação da criminalidade, os quais auxiliarão no uso racional dos recursos materiais e humanos e também na adoção de estratégias de ação operacional apropriadas.

A inteligência policial ou inteligência de segurança pública recebeu de Adriano Mendes Barbosa (2011, p. 13) a seguinte definição:

Ela, em veras, constitui uma forma diferenciada de abordagem
tática e estratégica da prevenção e repressão criminais utilizadas
quando há necessidade de se produzir, além de evidências (provas),
conhecimento tático e estratégico para enfrentamento da criminali-
dade organizada, com uma perspectiva macro e de longo prazo do
problema do crime e da criminalidade.

Observa-se com relação à inteligência policial um caráter de novidade no cenário brasileiro, sendo a necessidade de investimento maciça nessa área fruto do avanço da criminalidade organizada. Paralelamente ao crime organizado, a criminalidade "comum", combatida com os métodos tradicionais de investigação, continua em ascensão, o que exige da polícia a capacidade de lançar mão das novas técnicas sem olvidar as antigas. 
Mas é fato que a inteligência policial precisa evoluir, sobretudo em um mundo globalizado e interligado por redes de computadores, no qual o criminoso não tem rosto e pode estar a poucos metros ou a milhares de quilômetros de distância da cena do crime. E mais, tem o poder de se desvencilhar das provas com um simples comando no teclado do computador.

Essa necessidade de constante evolução da inteligência policial para fazer frente à criminalidade organizada é constatada por Celso Moreira Ferro Júnior (2008a, p.100):

À comunidade policial, e ousamos dizer à comunidade cientifica policial', incumbe trilhar o seu caminho para o futuro em meio a um ambiente selvagem de criminalidade crescente - ao mesmo tempo violenta e sofisticada, organizada e globalizada.

Todavia, o mesmo autor (FERRO JÚNIOR, 2008a, p. 100) reconhece que a evolução da atividade de inteligência policial não pode se dar aleatoriamente, apenas com o incremento de técnicas especiais e equipamentos modernos, mas há que ter compromisso sério com um planejamento que conserve as inúmeras variáveis.

Resta claro, no pronunciamento do autor, a necessidade de um engajamento da inteligência policial com uma política não apenas penal, mas multidisciplinar que contemple o problema da criminalidade sob todos os seus aspectos. Esse engajamento, no Estado Democrático de Direito, não pode dar-se de outra maneira se não respeitando as garantias e direitos fundamentais inscritos na Constituição Federal.

Uma forma segura para que a atividade de inteligência policial atue segundo critérios democráticos é a sua vinculação a uma política criminal constitucional voltada para os fundamentos da república e com foco na prevenção criminal, ainda que para a consecução desse intento seja necessária a troca de saberes com diversas áreas do conhecimento, alheias à rotina policial.

Afinada com esse entendimento, a Secretaria Nacional de Segurança Pública - SENASP propõe entre os princípios da atividade de inteligência de segurança pública o seguinte (in FERRO JÚNIOR, 2008a, p. 153): “O referencial ético será o próprio artigo $1^{\circ}$ da Constituição Federal, segundo o qual o Órgão de Inteligência (OI) tem por missão informar para preservar o Estado Democrático de Direito e defender a sociedade." 
É latente, pelas explicações aqui apresentadas e pela própria posição estatal apresentada pela SENASP que a atividade de inteligência policial, independentemente de quaisquer alterações no arcabouço legal, seja constitucional ou infraconstitucional, está obrigatoriamente vinculada a uma política criminal que respeite a dignidade do ser humano. Diga-se, a uma política criminal do ser humano.

No âmbito do Departamento de Polícia Federal - DPF se define inteligência policial como:

A atividade interativa exercida pelo órgão policial fundamentada em preceitos legais e padrões éticos, que consiste na produção e proteção de conhecimentos, por meio de metodologia própria e de técnicas acessórias, que permitam afastar a prática de ações meramente intuitivas e a adoção de procedimentos sem uma orientação racional. (Citado por Joanisval Brito Gonçalves, 2010, p. 30).

Nota-se que a definição adotada no âmbito do Departamento de Polícia Federal, embora prime pela legalidade e ética, pode alçar a um novo patamar, fornecendo à atividade de inteligência a segurança proporcionada pela vinculação aos valores maiores da República Federativa do Brasil, presentes na Constituição.

Uma forma de tornar visível e respeitável esse alinhavar constitucional é a submissão da inteligência policial a uma política criminal de Estado e voltada para a dignidade humana, como preconizada neste trabalho.

Celso Moreira Ferro Júnior (2008b, p. 52) embora tenha demonstrado previamente preocupação com todas as variáveis na formulação de políticas de segurança pública, incluindo a atividade de inteligência, deixa de abordar em seu conceito de inteligência policial até mesmo a questão legal e ética, o que aponta para a novidade do tema aqui proposto.

A preocupação com a aliança entre inteligência policial e uma política criminal voltada para a valorização da dignidade do ser humano deve ser de tal monta que sua visualização não se restrinja à atividade de maneira genérica, mas esteja visível em cada desdobramento dessa atividade, como na busca de dados negados por meio de operações de inteligência.

Tais operações se utilizam de técnicas especiais de investigação visando confirmar evidências, indícios e obter conhecimentos sobre a atuação 
criminosa. Portanto, uma vez que têm o potencial de invasão da esfera de intimidade do indivíduo, não podem descuidar sequer por um instante do valor dignidade humana.

Adriano Mendes Barbosa (2011, p. 17) após definir operações de inteligência policial nos mesmos moldes dos acima referidos, aponta, de forma extremamente apropriada, o vínculo que deve guardar essas operações com os fundamentos constitucionais. Diz: "Outrossim, há de se frisar que todas as diligências investigativas levadas a efeito na seara das Operações de Inteligência policial hão de ser conduzidas sob a égide dos ditames do Estado Democrático de Direito."(negritos do autor).

Com os olhos bem abertos para a necessidade de a atividade de inteligência primar pela legalidade estrita em todos os momentos de seu agir, Adriano Mendes Barbosa (2011, p. 17) apresenta receita de aplicação imediata e irrestrita:

A atividade de Inteligência aplicada em suporte à açôes de prevenção e repressão criminal busca, em última instância, a formação de evidências que vão dar suporte ao nascimento da prova em sede processual, e estas, por conseguinte, não podem ser concebidas ainda em seu nascedouro sob o manto da ilegalidade ou da ilegitimidade. Neste diapasão, toda e qualquer diligência que invista sobre direitos protegidos por sigilo há de ser conduzida mediante autorização da ordem judicial devida."

A atividade de inteligência policial como ramo da inteligência, não carece sequer de fundamento legal novo para se lançar rumo à frutífera aliança com a política criminal do ser humano. Isso porque a Lei $\mathrm{n}^{\circ} 9.883 / 99$, que trata do sistema brasileiro de inteligência é esse elo e, definitivamente, prima pela preservação da dignidade da pessoa humana. Diz o seu artigo $1^{\circ}$ e parágrafo $1^{\circ}$ :

O Sistema Brasileiro de Inteligência tem como fundamentos a preservação da soberania nacional, a defesa do Estado Democrático de Direito e a dignidade da pessoa humana, devendo ainda cumprir e preservar os direitos e garantias individuais e demais dispositivos da Constituição Federal, os tratados, convenções, acordos e ajustes internacionais em que a República Federativa do Brasil seja parte ou signatário, e a legislação ordinária.

Que a atividade de inteligência policial, com o fim de acompanhar e até se adiantar às manifestações do crime organizado precisa ser alvo de po- 
líticas legais específicas, a exemplo das Leis n ${ }^{\circ}$ 12.737/2012 e 12.965/2014, é conclusão que facilmente se chega, sobretudo porque as ações do Estado, inclusive no enfrentamento da criminalidade, devem estar amparadas sob o manto da legalidade.

Todavia, somente o amparo da legalidade estrita não é suficiente, tendo em vista essa atividade imiscuir-se em direitos ditos fundamentais do cidadão, seja ele criminoso ou não. Daí a atividade de inteligência policial necessitar estar assentada na própria Constituição e em políticas criminais afinadas com a ordem constitucional. Essa constitucionalização da atividade de inteligência obviamente resultará em maior segurança à atividade e aos agentes, bem como no fortalecimento de provas produzidas em futuros inquéritos policiais que tenham origem em relatórios oriundos dessa atividade de inteligência.

Muito embora exista respaldo constitucional e legal para a adoção de uma inteligência policial humanizada - conforme argumentos acima -, esse posicionamento precisa ser amadurecido no Brasil.

Enquanto isso, a atividade de inteligência policial literalmente corre atrás do prejuízo quando o tema é a aceitação nos tribunais e outras instâncias estatais dos conhecimentos por ela produzidos. Certeza de que estamos diante de um problema atual são as inúmeras anulações de provas, de inquéritos e processos judiciais, sob a justificativa de ofensa a direitos e garantias individuais durante as operações de inteligência.

Pergunta necessária para a minimização desse problema seria: "qual o modelo de política criminal capaz de oferecer à atividade de inteligência a segurança de constitucionalidade e de respeito aos direitos humanos, valores tão caros no Estado Democrático de Direito?”.

Estamos convictos de que uma política que alcance tal desiderato deve ter como finalidade a prevenção do crime, com foco na dignidade da pessoa humana. Estamos falando aqui de uma política criminal do ser humano, na acepção de Manuel Monteiro Guedes Valente (2013, p. 81-82).

Uma vez que dispomos de um modelo a nosso ver aceitável de política criminal, a questão seguinte seria: "que caminhos poderiam levar a atividade de inteligência policial a se adequar a essa política criminal do ser humano?" 
A resposta parece-nos residir no controle e na legislação. Nas palavras de Joanisval Brito Gonçalves (2010, p. 13): “Uma vez que se admita a delegação como alicerce do regime democrático, o controle torna-se importante para se evitar ou restringir o principal risco dessa delegação de poder: a possibilidade de que o agente volte-se contra os interesses de quem delega."

Com o intuito de esclarecer a forma que deve se dar esse controle nas sociedades democráticas, Joanisval Brito Gonçalves (2010, p. 17) desenvolve a definição de accountability como sendo um valor fundamental, e que significa, em linhas gerais, a obrigação do agente público de responder por seus atos e explicar sua conduta.

No que tange ao controle da atividade de inteligência, Joanisval Brito Gonçalves (2010, p. 19) assevera:

Registre-se que accountability torna-se muito mais relevante em situaçôes onde a transparência é limitada por comprometer, por exemplo, a segurança nacional - como ocorre com a atividade de inteligência. Dai se dizer que determinada ação ou conduta, ainda que não possa ser transparente para o público em geral, deve estar sujeita ao controle daqueles legal ou constitucionalmente competentes para isso.

Segue o autor (GONÇALVES, 2010, p. 41) a explanar acerca da importância do controle, que, no seu entender tem outras contribuições, entre elas evitar abusos por parte dos órgãos e aumentar a aceitação desses órgãos e de seus agentes pela sociedade civil.

Ponto essencial acerca do controle da atividade de inteligência é a observação de seu caráter sigiloso e sua importância para a manutenção do próprio Estado, daí concordarmos com o referido autor (GONÇALVES, 2010, p. 51) quando conclui: “De toda maneira, o que é importante estar claro é que deve haver controle, mas também esse controle não pode constituir obstáculo para a atividade de inteligência, imprescindível para o Estado.”

Certos estamos que o tema do controle da atividade de inteligência apresenta inúmeras nuances, as quais são tratadas na obra de Joanisval Brito Gonçalves (2010) de forma bastante abrangente. Todavia, para os objetivos deste trabalho supre a constatação aqui apresentada, da necessidade de controle efetivo da atividade de inteligência para que 
esta possa se apresentar como ferramenta útil à efetivação de uma política criminal apropriada ao Estado Democrático de Direito e afinada com o respeito à dignidade humana.

Com o fito de tornar plausível o controle referido, deve este se apoiar na Constituição e no arcabouço legal. Esse é o entendimento apresentado por Joanisval Brito Gonçalves (2010, p. 111) e aqui acolhido, ao aconselhar que o papel do serviço de inteligência já esteja explicitado no texto constitucional. $\mathrm{O}$ mesmo autor entende, ainda, que a legislação brasileira sobre o assunto é incipiente (GONÇALVES, 2010, p. 148).

O caminho para se levar a inteligência a um instrumento da política criminal do ser humano precisa ser bem sedimentado, afinal, uma atividade que depende do sigilo para seu êxito, carece de amarras democráticas muito sólidas para não correr o risco de descarrilar para o campo da perseguição, favorecimento pessoal, favorecimento político, ilegalidade.

A constitucionalização da atividade de inteligência, com todos os desdobramentos infraconstitucionais possíveis apresenta-se como o caminho mais apropriado à sua retirada das sombras e dignificação da atividade, essa de importância tão peculiar ao Estado Democrático de Direito.

Joanisval Brito Gonçalves (2010, p. 194), frise-se, compartilha dessa idéia: "Alternativa interessante, portanto, para tornar mais evidente o papel da atividade de inteligência em defesa da sociedade e do Estado democrático, seria elevar o tema à esfera constitucional."

O autor consegue ser ainda mais explícito ao afirmar (GONÇALVES, 2010, p. 199):

Assim, difícil operar em inteligência sem respaldo legal. O estabelecimento de uma legislação em que esteja claro o que se pode e o que não se pode fazer facilita em muito o controle por parte das autoridades públicas e da própria sociedade, ao mesmo tempo em que inibe eventuais práticas delituosas por parte de pessoas dos serviços secretos.

Como ocorre atualmente, a atividade de inteligência, sobretudo a inteligência policial, é desempenhada por servidores públicos que utilizam técnicas especiais para a obtenção do dado negado e confecção dos relatórios que irão embasar decisões das mais altas cúpulas da polícia, em nível estratégico e operacional. 
A grande dificuldade para enquadrar essa atividade em moldes realmente democráticos é que as técnicas especiais utilizadas (especificamente falando), não encontram respaldo em qualquer lei. Daí, sempre que interesses de poderosos são atingidos, esses buscam fundamentar suas defesas em possíveis afrontas cometidas durante as operações de inteligência aos direitos e garantias individuais estatuídos na Constituição. Ressalte-se, no entanto, que alguns passos nessa direção já estão sendo dados, a exemplo da sanção da Lei $\mathrm{n}^{\circ} 12.965 / 2014$, que cria o marco civil da internet.

Temos então, uma atividade de extrema importância tolhida de sua funcionalidade pela linha tênue entre a legalidade e a ilegalidade em que atua. A maneira mais democrática e segura de dar o devido respaldo à atividade de inteligência policial seria a inserção dessas "técnicas especiais" em lei específica, com disciplina das autorizações necessárias à sua implementação. Tudo sem perder de vista o caráter sigiloso da atividade.

Com a regulamentação legislativa das técnicas de inteligência, a própria atividade sairia fortalecida e poderia contribuir de forma muito mais significativa para o combate da criminalidade e para a concretização de uma política criminal do ser humano.

\section{Redes Sociais da Internet e Delitos}

É bem remoto o entendimento de que o homem é um ser social. Durante a história da humanidade, esses relacionamentos sociais se desenvolveram formando redes, como redes de parentes, de vizinhos, redes de comerciantes, redes de profissionais, redes religiosas, entre muitas outras. Sendo assim, essas relações levadas a efeito pelas pessoas agem na estruturação da própria sociedade.

Essa constatação que o desenvolvimento social de longas datas se dá por meio de redes encontra respaldo em Manuel Castells (2005, p. 17) ao afirmar que o que é novo é o fato de o conhecimento e a informação serem de base microeletrônica, vez que a forma de organização social em redes é velha.

Em regra, as redes expandem-se com base em princípios como auto-organização, confiança, relações horizontais, ou seja, ausência de 
hierarquia. No interior dessas redes são trocadas informações, experiências, valores, e assim é construído o conhecimento, reforçadas práticas e, por fim, solidificada uma maneira de ver e se posicionar frente ao mundo inerente àquele grupo.

As redes, de modo geral, sofrem influência e influenciam outras redes, delimitando os contornos do tecido social. Outras não são as características das redes sociais desenvolvidas na era da informática. O mundo globalizado empurra-nos a uma realidade cada vez mais conectada, somos impelidos a engrossar as fileiras das redes virtuais. Nas palavras de Manuel Castells (2005, p. 18): "As redes de comunicação digital são a coluna vertebral da sociedade em rede."

Percebe-se que interesses, negócios, obrigações, migram para esse território virtual, compelindo as pessoas a se filiarem. De modo que está cada vez mais difícil ao homem comum se eximir da adesão a mais este tipo de rede social, as redes sociais da internet. Essa transformação social apresenta-se tão marcante e duradoura que Manuel Castells (2005, p. 18) refere-se à globalização como sinônima de sociedade em rede.

Chega-se assim à conclusão que os países vivem ou se encaminham a um verdadeira sociedade de rede, a qual recebe de Manuel Castells (2005, p. 20) a seguinte definição:

\section{A sociedade em rede, em termos simples, é uma estrutura social base- ada em redes operadas por tecnologias de comunicação e informação fundamentadas na microelectrónica e em redes digitais de compu- tadores que geram, processam e distribuem informação a partir de conhecimento acumulado nos nós dessas redes.}

Como em todo movimento social, diversas representações se fazem presentes nas redes virtuais. Entre elas, a criminalidade busca espaço neste mundo novo e, na ausência de todas as amarras legais necessárias, encontra terreno fértil às suas investidas.

No momento, então, em que os legítimos interesses sociais são violados, o Estado deve agir para garantir o direito à liberdade, à vida privada, à propriedade, entre outros direitos insculpidos na Constituição.

Os delitos cometidos no mundo virtual, incluindo as redes sociais, são de duas espécies. Aqueles delitos comuns positivados no Código Penal e 
leis extravagantes e os delitos de natureza nova, relativos apenas a este mundo virtual e sua novidade, devendo ser positivados para encontrar maior efetividade em seu combate.

Entre os delitos mais comuns perpetrados na internet estão a pirataria, o dano ao patrimônio, a sabotagem informática, a pornografia infantil, a apropriação indébita, o estelionato, a divulgação de segredo, a falsa identidade, a discriminação religiosa, de raça e de etnia, a difamação, calúnia e a injúria.

Observa-se, assim, que, em grande parte os delitos cometidos na rede mundial de computadores são os mesmos cometidos no mundo real, carecendo apenas que as leis existentes sejam adaptadas a esses crimes. Isso é o que vem fazendo os juízes e tribunais brasileiros ao condenarem, reiteradamente, essas condutas com base no arcabouço legal preexistente.

Eduardo Marcelo Castella (2005, p. 110) entende que essa nova criminalidade virtual refere-se a uma nova situação fática e jurídica onde um equipamento de informática pode ser meio e, também, objeto de delito, dando origem à classificação de delitos impróprios e próprios, respectivamente.

Esse mesmo autor identifica várias dificuldades inerentes à investigação dos crimes na internet (CASTELLA, 2005, p. 117):

Não bastando as dificuldades que cercam uma investigação no mundo real, na internet, existem outros impeditivos de se chegar ao criminoso, criando a possibilidade do crime perfeito. Tal consiste na facilidade em se apagar sinais, indicios e provas, camuflando ou eliminando os rastros deixados.

Diante desse mundo novo, de oportunidades e caminhos para a criminalidade, a polícia precisa agir. E, essa necessidade de ação irá inserir as instituições policiais de uma vez por todas no mundo virtual. Nesse ambiente, novas técnicas de investigação precisaram ser desenvolvidas, outras já existentes precisam ser aprimoradas e, na falta de uma disciplina legal com contornos bem definidos, abre-se espaço para diversas interpretações.

Alguns autores vêem como difícil e até inviável a efetivação de investigações no mundo virtual com estrita obediência à lei no estágio em que essa se encontra no tocante à internet, como Eduardo Marcelo Castella (2005, p. 121): 
Na prática, tem-se tornado inviável proceder a investigações sob a égide legal, ante o paradoxo em que se encontra a legislação, havendo pouco entendimento doutrinário e jurisprudencial. Anda-se sobre terreno movediço, e qualquer desatenção resulta na produção de provas sem efeito jurídico, com risco, ainda de incidir em abuso.

Eduardo Marcelo Castella (2005, p. 123- e 124) apresenta como forma de solucionar esse descompasso entre criminalidade na internet e ação policial a criação de leis específicas, a dotação das polícias de recursos tecnológicos avançados e de treinamento constante.

Posto está o problema. O relacionamento das pessoas por meio de redes sociais na internet trouxe consigo novos tipos penais (carentes de positivação) e novas formas de cometimento de antigos crimes, o que força a polícia a uma nova forma de agir.

Um aspecto chama bastante atenção, como as redes sociais são em sua maioria fontes abertas (conforme definição da inteligência policial), tem o seu acesso facilitado às polícias para investigações e operações de inteligência. Esse ponto reveste-se de grande relevância, sobretudo para a atividade de inteligência que, atualmente discute a importância dessas fontes abertas para a produção do conhecimento de interesse.

Nesse rumo se manifestou na Revista Brasileira de Inteligência, Leonardo Singer Afonso (2006, p. 56):

Fica óbvio que a grande vantagem das fontes abertas é o alto grau de oportunidade e o baixo custo para obtê-las. A OSINT [Inteligência de fontes abertas] torna-se atraente principalmente em épocas de contingenciamento orçamentário e para aquelas nações que adotam o princípio da efetividade em seu arcabouço jurídico. Ampliam, portanto, as possibilidades da atividade de Inteligência.

Vemos por um lado a investigação policial apontando a linha tênue que separa legalidade e ilegalidade no combate à criminalidade da internet (incluem-se por óbvio as redes sociais). Por outro lado, a atividade de inteligência aponta a grande utilidade dos dados produzidos nas redes sociais, sobretudo pela facilidade de acesso.

No centro dessas questões encontra-se, então, o modo de atuar da polícia e, especificamente para os objetivos deste trabalho, da inteligência policial. 
Restou claro pelo acima exposto que as redes sociais não são um ente estranho à sociedade e ao Estado, mas, tão somente, uma nova forma de expressão social, que, obrigatoriamente, deve se coadunar com a forma de Estado, forma de Governo, o Sistema de Governo e com o Regime Político adotados pelo país.

No caso do Brasil, qualquer interferência governamental nas redes sociais deve observar os ditames do Estado Democrático de Direito e respeitar os preceitos constitucionais dos direitos e garantias individuais, sob o risco de, não agindo assim, tais interferências tenderem para um autoritarismo refutado veementemente por nossa Carta Magna.

\subsection{Inteligência Policial e Redes Sociais na Óptica da Política Criminal do Ser Humano}

$\mathrm{Na}$ mesma velocidade que implementam as redes de comunicação no mundo virtual da internet, especialistas desenvolvem ferramentas para ler essas informações e interpretá-las conforme o interesse do cliente.

As grandes corporações, indústrias, comércio, serviços, se interessam em conhecer o perfil dos usuários das redes sociais. Os gostos dos clientes em potencial. Visam desenvolver produtos e oferecer serviços que atendam aos anseios da sociedade. Para isso, contratam empresas que consigam captar esses dados expostos nas redes sociais (em sua maioria abertos), e traduzi-los em termos de preferências e tendências.

As empresas não são as únicas que se interessam por essa leitura. Políticos, Estados, Polícias, Organizações criminosas, engrossam essa fila dos clientes das análises das redes sociais. Nessa guerra de interesses, pessoas e instituições especializadas no desenvolvimento de ferramentas que leiam esses dados, se multiplicam. Uns à procura de lucro, outros do desenvolvimento científico, outros apenas para satisfazer o interesse de conhecer detalhes da vida e relações das demais pessoas e outros, ainda, para cometer e facilitar o cometimento de crimes.

Nesse ponto faz-se necessário um esclarecimento. A grande maioria dos usuários das redes sociais não tem ciência de que seus dados estão sendo monitorados ininterruptamente. A mesma sensação de liberdade existente nas redes é replicada para uma sensação de segurança. 
Isso se dá porque na comunicação por meio da internet temos o fenômeno, já citado acima, da horizontalidade, no qual as pessoas se comunicam sem que haja a necessidade de um intermediário oficial. Manuel Castells (2005, p. 24) apresenta de maneira clara esse entendimento:

A comunicação entre computadores criou um novo sistema de redes de comunicaşão global e horizontal que, pela primeira vez na história, permite que as pessoas comuniquem umas com as outras sem utilizar os canais criados pelas instituiçôes da sociedade para a comunicação socializante.

O Estado, por sua vez, precisa entender esse fenômeno e respeitá-lo como parte da marcha inevitável da história. O que ocorre atualmente no Brasil, todavia, é que a polícia, como um dos inúmeros interessados nos dados veiculados nas redes sociais, na busca por acompanhar as transformações experimentadas pelo fenômeno criminal e desempenhar o seu papel, mergulha neste mar de informações, nessa teia de contatos, à procura de seguir os rastros deixados pelos criminosos, que se alastram pela rede numa velocidade vertiginosa.

Eis a questão. Das inúmeras ferramentas existentes no mercado, oferecidas, às vezes, de forma gratuita na própria rede mundial de computadores, várias se utilizam de expedientes ilegais e/ou imorais, para captar os dados dos usuários.

Deve então a polícia se questionar acerca do preço a ser pago para a consecução desses dados. Se entre as repostas existir apenas um arranhão, por menor que seja nos direitos e garantias individuais e coletivos inscritos na Constituição, ou a menor ofensa à dignidade da pessoa humana, essas ferramentas devem ser rejeitadas veementemente e até investigadas como instrumentos de possível prática de crime.

Qual seria então um caminho aceitável para que a polícia, por meio de suas unidades de inteligência, pudesse operar nas redes sociais sem infringir as normas do Estado Democrático de Direito? Entre as respostas possíveis certamente está a atuação como polícia cidadã, nos moldes do caput do art. 144 da Constituição Federal de 1988, na busca pela preservação da ordem pública, da incolumidade das pessoas (entenda-se incolumidade do modo mais elástico que o termo permite no Estado Democrático de Direito) e do patrimônio. 
Traduzindo de maneira prática a contribuição acima, a polícia precisa especializar seus quadros para conhecer as diversas ferramentas e redes sociais existentes, em bases científicas. De posse desse conhecimento, deve capitanear o debate na busca da construção de uma legislação que atenda aos ditames democráticos, mas que também lhe permita cumprir com seu papel. Esse papel cabe à polícia e, somente quando esta instituição se der conta de que não serve a governos e sim ao Estado, ocupará o lugar e o respeito que lhe cabe na ordem social.

Enquanto essa legislação não surge, existem dois caminhos, todavia somente um é digno de uma Polícia e de uma Inteligência democráticas. O primeiro, amplamente divulgado entre os "investigadores" particulares é a utilização de tudo o que está "disponível” nas redes sociais no afã de solucionar o maior número de casos possíveis. $\mathrm{O}$ segundo, mais sóbrio, mais digno de uma sociedade e de uma polícia consciente da longa jornada histórica que lhe trouxe até este momento, jornada por vezes banhada no sangue de inocentes, é a defesa veemente dos princípios democráticos e atuação nos estritos limites da constitucionalidade, da legalidade e da moralidade. Ainda que esse atuar represente a impunidade de certo número de criminosos.

Afinal, nossa democracia está em construção e, durante essa obra, muitos tijolos se quebrarão. Não serão perdidos, pois, sempre podem servir de base a mais um pavimento. E como afirmado por Manuel Castells (2005, p. 26): "A sociedade em rede não é o futuro que devemos alcançar como próximo estádio do progresso humano, ao adoptarmos o paradigma das novas tecnologias. É a nossa sociedade, em diferentes graus e com diferentes formas dependendo dos países e das culturas."

\section{Consideraçốes Finais}

Longa jornada nos trouxe até esse momento de considerações, as quais embora recebam o nome de finais, devem servir apenas para lançar luz sobre o debate de tema tão necessário na atualidade: o papel da polícia quanto à defesa e o respeito pela dignidade humana.

Tarefa extremamente complexa nos impusemos, traçar uma coluna vertebral que una as Redes Sociais, a Inteligência Policial e a Política Criminal na preservação da dignidade da pessoa humana sob o manto do Estado Democrático de Direito. 
Não há como falar em Estado democrático sem voltar os olhos para a própria democracia. E, na democracia moderna, segundo os ensinos de Norberto Bobbio (2000, p. 380) o soberano não é o povo considerado em conjunto, mas todos os cidadãos, ou seja, cada indivíduo. Dessa maneira assume extrema relevância o respeito e a proteção que se deve dar aos direitos e garantias constitucionais cabíveis a cada membro da coletividade com o fim de realizar a democracia no Estado.

O mesmo autor (BOBBIO, 2000, p. 386) leciona que democracia pode ser definida como "poder em público", de modo que os governados tenham condições de conhecer os atos dos governantes. Acrescente-se, que todos os cidadãos conheçam as regras de convivência em dado Estado. O contrário dessa clareza pode ser encontrado nos governos autocráticos nos quais o povo é desprezado e, como conseqüência lhe é usurpado o direito de conhecer.

Transpondo essa necessidade de clareza para a seara criminal, importa que os indivíduos - criminosos, vítimas, sociedade indiretamente afetada pelo ato criminoso - têm o direito de conhecer todo o processo de formação das convicções e impulsionadores das estratégias de ação, seja dos julgadores, administradores, governantes ou legisladores.

Com o intuito de oferecer resposta à indagação de como se tornaria possível ao indivíduo manter-se previamente informado acerca dos métodos investigativos implementados pelo Estado, e de outro lado, como poderia esse Estado levar a efeito suas investigações no mundo virtual das redes sociais de computadores com respeito aos direitos e garantias individuais e ainda promovendo a dignidade da pessoa humana, propusemos a adoção da Política Criminal do Ser Humano, conforme preconizada por Manuel Monteiro Guedes Valente (2013).

Essa política criminal de bases constitucionais teria como um dos seus principais executores e defensores a polícia, que tem o papel constitucional de preservar a incolumidade das pessoas. Veja que essa defesa deve se dar em face de qualquer violação, seja por parte de criminosos, seja por parte dos próprios órgãos estatais. Essa polícia constitucional se apercebe do seu papel na manutenção da ordem democrática, no qual recebe ordens dos governantes, legisladores, administradores, mas, apenas as executa se alinhadas com os ditames constitucionais. 
Tal assertiva pode soar estranha, sobretudo se estivermos imersos em uma realidade em que os órgãos policiais se vêem apenas como executores ocupantes de um patamar abaixo da linha de decisão. Essa é a cultura que precisa ser rompida. Esse é o enorme desafio que nos aguarda enquanto agentes da lei, mas antes, agentes e defensores da Constituição.

Essa política criminal que respeita e defende o ser humano deve estar presente em todas as ações policiais seja de investigação, administração ou inteligência. Especificamente no ramo inteligência policial cabe extrema atenção considerando o caráter secreto típico da atividade.

A questão seguinte é como conciliar a atividade de inteligência com a dignidade da pessoa humana, sobretudo no ambiente ímpar das redes sociais de computadores.

Esse tema que ocupou o centro das discussões neste trabalho levou à constatação de que o caminho mais democraticamente seguro se dá com a positivação em leis de todos os procedimentos de inteligência com potencial de interferir na liberdade e vida privada do indivíduo. Além ainda, a elevação da atividade de inteligência ao nível constitucional, tendo em vista a sua extrema importância na defesa da sociedade e do próprio Estado é medida que se faz necessária o quanto antes.

Por outro lado, a adoção de mecanismos legais claros e específicos de controle da atividade espantará de vez qualquer margem que possa existir para uma atuação inconstitucional.

No âmbito das redes sociais de computadores muito mais importante este debate, uma vez que existe um vasto território livre de regulação e, se não for o respeito aos direitos e garantias assegurados constitucionalmente aos cidadãos, outras amarras não impedirão servidores inescrupulosos de cometerem todo tipo de abuso, sob o manto da necessidade de fazer cessar ações criminosas.

Não fazemos aqui apologia à uma polícia leniente com a criminalidade, mas defendemos uma polícia que saiba reconhecer o seu papel constitucional - e o grande caminho que trouxe nosso país a este momento democrático - e não se curve nem mesmo diante da possibilidade de obter de maneira fácil dados capazes de conduzir criminosos à cadeia. 
Uma verdade deve estar muito clara na mente de todo policial - aqui enfatizamos os policiais de inteligência - criminosos surgirão sempre no meio da sociedade, de modo que se um escapa hoje à ação policial, novas táticas podem ser implementadas para que êxito seja conseguido amanhã. Mas uma democracia madura, na qual nenhum cidadão tenha receio de ser vítima de seu companheiro alçado a posto de autoridade - por ser-lhe e considerar-se servo como de resto a toda a sociedade que o nomeou - demora gerações e muitas vidas para ser construída, cabendo a cada um de nós depositar um tijolo que seja para a continuidade dessa grande obra da humanidade.

Resumimos então essas breves reflexões acerca do papel da inteligência policial junto às redes sociais em uma perspectiva da política criminal do ser humano com o esquema seguinte:

1 - A sociedade atual se relaciona em grande parte por meio das redes sociais de computadores.

2 - Os criminosos se aproveitam dessas redes para praticarem diversos tipos de crimes.

3 - A polícia, por meio de seus serviços de inteligência procura conhecer esse meio para poder combater à criminalidade.

4 - A Política Criminal do Ser Humano dota a inteligência policial das ferramentas necessárias para agir nesse novo mundo sem ferir os princípios constitucionais.

5 - A ação da polícia levada a efeito pela inteligência policial é construída em bases sólidas, porque constitucional e portanto exerce duplo papel: combater a criminalidade e zelar pela dignidade da pessoa humana.

6 - A constitucionalização e o controle da atividade de inteligência leva à sociedade a segurança necessária de que embora não estejam vendo os métodos e técnicas utilizados - por serem próprios da atividade - existem cidadãos nomeados pelo povo (em uma das formas permitidas pela constituição) que realizam efetivamente tal controle.

Não podemos estranhar de maneira nenhuma que tais propostas estejam sendo apresentadas justamente quando o tema é inteligência policial. Afinal, como já referido, a democracia implica no poder do povo conhecer os destinos dados à nação pelos seus mandatários. Assim, mesmo em áreas con- 
sideradas sigilosas, sensíveis, esse sigilo não pode ultrapassar o estritamente necessário e, completamente, disciplinado em lei e controlado.

Uma verdade deve estar estampada a todos aqueles que cuidam da coisa pública: todo o poder emana do povo.

IVON JORGE DA SILVA

Delegado de Polícia Federal. Bacharel em Direito, Especialista em Inteligência Policial pela Escola Superior de Polícia da Academia Nacional de Polícia.

\title{
Police Intelligence and Networks: the Federal Police towards a constitu- tionally sustainable Policy
}

\begin{abstract}
The activity of police intelligence is at the center of international debate, especially with the advent of globalization and the development of social relations increasingly leveraged through computer network. As a result, new techniques need to be implemented by the police to tackle crime that goes steeply in the virtual world. In this context, questions of various natures, but the democratic rule of law, a weighting that can not stand on the sidelines with respect to the protection of human dignity and in parallel with the police in this protection. In seeking to establish this balance between the role of the police in combating the new crime and necessary protection of human dignity even in this new environment, stands with vital criminal policy, which guides the tools adopted by the State in preventing and combating crime. In this sense, the question that should follow this guidance criminal policy and on what basis should be established so that is consistent with the stage of democracies and the Rule of Law that posit the guarantee of human rights. It is concluded that to meet the Brazilian constitutional provisions, the acting police intelligence must be anchored in a constitutional criminal policy that focuses on human dignity and center: a criminal policy of human being.
\end{abstract}

KEYwORDS: Crime. Democracy. Rule of law. Criminal Policy. Police. Police Intelligence. Social Networks.

\section{REFERÊNCIAS}

AFONSO, Leonardo Singer. Fontes Abertas e Inteligência de Estado. In Revista Brasileira de Inteligência / Agência Brasileira de Inteligência Volume 2, Número 2. Brasília: Agência Brasileira de Inteligência, 2006. 
BARBOSA, Adriano Mendes. A Atividade de Inteligência de Segurança Pública. Revista Brasileira de Ciências Policiais. Brasília: ANP/ PF, Vol. 2, n. ${ }^{\circ}$ 1, Jan/Jun/2010, pp. 11-30. ISSN 2178-0013.

BECCARIA, Cesare. Dos Delitos e das Penas (tradução Jeremy Lugros). São Paulo: Editora Nilobook, 2013.

BOBBIO, Norberto. As Ideologias e o Poder em Crise. Brasília: Editora Universidade de Brasília, 3a edição, 1994.

BOBBIO, Norberto. Teoria Geral da Política: A Filosofia Política e as Lições dos Clássicos. Rio de Janeiro: Elsevier, 2000 - 20a reimpressão.

BRASIL, Constituição(1988). Constituição da República Federativa do Brasil. Brasília: Senado Federal, Subsecretaria de Edições Técnicas, 2007.

CARVAlHO, Américo Taipa de. Direito Penal Parte Geral: Questões Fundamentais Teoria Geral do Crime. Coimbra: Coimbra Editora, 2a edição, 2011.

CASTELLA, Eduardo Marcelo. Investigação Criminal e Informática Inteligência Artificial x Boletim de Ocorrência. Curitiba: Juruá, 2005.

CASTELLS, Manuel. Sociedade em Rede: do Conhecimento à Política. In Debates da Presidência da República: Do Conhecimento à Acção Política. Conferência Promovida Pelo Presidente da República. Organizado por Manuel Castells e Gustavo Cardoso. Belém: 2005. Em <http://biblio.ual. pt/Downloads/REDE.pdf $>$. Acesso em: 02 de abril de 2014.

CASTELO BRANCO. José Henrique. Relato das Experiências de Intranet no Setor Público de Minas Gerais. Belo Horizonte: Escola de Governo da FJP, 2000.

CASTRO, Clarindo Alves de; RONDON FILHO, Edson Benedito. (Coord). Inteligência de Segurança Pública: Um Xeque - Mate na Criminalidade. Curitiba: Juruá, 2009.

FERRI. Enrico. Princípios de Direito Criminal: O Criminoso e o Crime (tradução Luiz de Lemos d' Oliveira). Campinas/SP: Russel editores, $3^{a}$ edição, 2009.

FERRO JÚNIOR, Celso Moreira et al. Segurança Pública Inteligente: Sistematização da Doutrina e das Técnicas da Atividade. Goiânia: Kelps, 2008a. 
FERRO JÚNIOR, Celso Moreira. A Inteligência e a Gestão da Informação Policial: Conceitos, Técnicas e Tecnologias Definidos pela Experiência Profissional e Acadêmica. Brasília: Fortium, 2008b.

GONÇALVES, Joanisval Brito. Atividade de Inteligência e Legislação Correlata. Niterói/RJ: Ímpetus, 2011.

GONÇALVES, Joanisval Brito. Políticos e Espióes: O Controle da Atividade de Inteligência. Niterói/RJ: Ímpetus, 2010.

LISZT, Franz Von. Tratado de Direito Penal Allemão (tradução José Hygino Duarte Pereira). Rio de Janeiro: Senado Federal, Conselho Editorial: Superior Tribunal de Justiça, 2006.

MITNICK, Kevin D.; SIMON, William L. A Arte de Enganar. São Paulo: Pearson Education, 2003.

SHECAIRA, Sérgio Salomão. Criminologia. São Paulo: Revista dos Tribunais, 5a edição, 2013.

SILVA, Germano Marques da. Curso de Processo Penal I. Lisboa/São Paulo: Editora Verbo, 4ª edição, 2000.

VAlente, Manuel Monteiro Guedes. Do Ministério Público e da Polícia. Prevenção Criminal e Ação Penal como Execução de uma Política Criminal do Ser Humano. - Lisboa: UCE, 2013a.

VALENTE, Manuel Monteiro Guedes. Segurança um Tópico Jurídico em Reconstrução. - Lisboa: Âncora Editora, 2013b. 